\title{
INDUCED AND LOGARITHMIC DISTANCES WITH MULTI-REGION AGGREGATION OPERATORS
}

\author{
Víctor G. ALFARO-GARCÍA ${ }^{1^{*}}$, José M. MERIGÓ ${ }^{2,3}$, Leobardo PLATA-PÉREZ ${ }^{1}$, \\ Gerardo G. ALFARO-CALDERÓN ${ }^{4}$, Anna M. GIL-LAFUENTE ${ }^{5}$ \\ ${ }^{1}$ Facultad de Economía, Universidad Autónoma de San Luis Potosí, San Luis Potosí, México \\ ${ }^{2}$ Departamento de Control de Gestión y Sistemas de Información, \\ Universidad de Chile, Santiago de Chile, Chile \\ ${ }^{3}$ School of Systems, Management, and Leadership, Faculty of Engineering and Information \\ Technology, University of Technology Sydney, Ultimo 2007, NSW, Australia \\ ${ }^{4}$ Facultad de Contaduría y Ciencias Administrativas, Universidad Michoacana \\ de San Nicolás de Hidalgo, Morelia, México \\ ${ }^{5}$ Facultat d'Economia i Empresa, Universitat de Barcelona, Barcelona, Spain
}

Received 26 May 2018; accepted 25 November 2018

\begin{abstract}
This paper introduces the induced ordered weighted logarithmic averaging IOWLAD and multiregion induced ordered weighted logarithmic averaging MR-IOWLAD operators. The distinctive characteristic of these operators lies in the notion of distance measures combined with the complex reordering mechanism of inducing variables and the properties of the logarithmic averaging operators. The main advantage of MR-IOWLAD operators is their design, which is specifically thought to aid in decision-making when a set of diverse regions with different properties must be considered. Moreover, the induced weighting vector and the distance measure mechanisms of the operator allow for the wider modeling of problems, including heterogeneous information and the complex attitudinal character of experts, when aiming for an ideal scenario. Along with analyzing the main properties of the IOWLAD operators, their families and specific cases, we also introduce some extensions, such as the induced generalized ordered weighted averaging IGOWLAD operator and Choquet integrals. We present the induced Choquet logarithmic distance averaging ICLD operator and the generalized induced Choquet logarithmic distance averaging IGCLD operator. Finally, an illustrative example is proposed, including real-world information retrieved from the United Nations World Statistics for global regions.
\end{abstract}

Keywords: OWA, decision-making science, logarithmic OWA operators, multiregion AGOP, induced OWA operators, distance OWA operators, induced distance logarithmic AGOP.

JEL Classification: C44, D81, M20.

*Corresponding author. E-mail: valfaro06@gmail.com

This is an Open Access article distributed under the terms of the Creative Commons Attribution License (http://creativecommons. org/licenses/by/4.0/), which permits unrestricted use, distribution, and reproduction in any medium, provided the original author and source are credited. 


\section{Introduction}

A region is conventionally defined as a part or portion of a whole space, which is characterized by having no fixed boundaries. Currently, the effects of global economic trade and its implications are widely observable (Grossman \& Helpman, 2015). These effects eliminate the imaginary borders that limit countries in generating and distributing value and affect the ways that innovation, growth and economic development are generated (Acemoglu, 2009; Florida, Gulden, \& Mellander, 2008; Grossman \& Helpman, 1993). These issues have attracted considerable attention to regions. Currently, more researchers are focusing their efforts on studying the economic, political and social influences that regions exert over territories from different but convergent perspectives, e.g., the regional effects that the twin notions of creative class and creative capital have over territories (Florida, 2002, 2005; Florida, Mellander, \& Stolarick, 2008), the economic implications of innovation and the Schumpeterian regional view (Batabyal \& Yoo, 2018), the regional influence that regions exert over companies (Sucháček, Sed’a, Friedrich, \& Koutský, 2017), and the social factors involving educational and regional growth (Lv, Yu, Gong, $\mathrm{Wu}, \& \mathrm{Xu}, 2017)$.

The continuously increasing number of elements to be modeled when assessing regions requires the design of new tools that aid decision-makers to achieve feasible solutions when a wide set of alternatives, heterogeneous information, and human attitudinal information need to be assessed. One of the most well-known information fusion techniques designed for decision-making is the ordered weighted average (OWA) operator (Yager, 1988). This operator and the parameterized families proposed have been widely studied and applied in a plethora of academic fields see e.g. (Beliakov, Bustince, \& Calvo, 2016; Beliakov, Pradera, \& Calvo, 2007; He, Wu, Yu, \& Merigó, 2017). Some of the main advantages of the OWA operator is the useful representation of the attitudinal character of the decision-maker in decision making problems (Zeng, Su, \& Zhang, 2016). The OWA operator was used as a motivation to build a more complex operator denominated the induced ordered weighted average (IOWA) operator (Yager \& Filev, 1999). The benefits of this last operator rely in the addition of an induced vector that affects the ordering mechanism of the arguments assessed (Yager, 2003). Such reordering allows the modelling of the problem to be inclusive also for the complex attitude of the decision makers (Chiclana, Herrera-Viedma, Herrera, \& Alonso, 2007), therefore being able to deal with even more complex problems which gives a closer resemblance of real-world situations. The extensions of the induced OWA have also included developments on fuzzy numbers (S. J. Chen \& S. M. Chen, 2003), intuitionistic fuzzy group decision making approaches designed to treat uncertain and vague information (Wei \& Zhao, 2012; Zeng, Llopis-Albert, \& Zhang, 2018), and linguistic information (Xian, Sun, Xu, \& Gao, 2016).

The conception of an ideal set of arguments to be reached compared to a set of options is a long and well-studied issue in decision making science. Here the notion of distance plays a decisive role. Some commonly utilized distance measures are e.g. the Minkowski, the Hamming, the Euclidean distances and the Hausdorff metric (Zwick, Carlstein, \& Budescu, 1987). In this work we utilize the Hamming distance (Hamming, 1950). It is of no surprise that this metric has gained popularity among scientists. The idea of considering the importance of each deviation value and including it as part of the information fusion techniques has led to the appearance of noted operators such as the ordered weighted distance (OWD) operators 
(Xu \& Chen, 2008) and the ordered weighted averaging distance (OWAD) operators (Merigó $\&$ Gil-Lafuente, 2010). From these classic operators several extensions have been developed, such as the consideration of intuitionistic fuzzy information IFOWD operator (Zeng \& Su, 2011), moving averages (León-Castro, Avilés-Ochoa, Merigó, \& Gil-Lafuente, 2018; Merigó \& Yager, 2013), Bonferroni means (Blanco-Mesa, León-Castro, \& Merigó, 2018), among others. More recently, the application of the induced vector has been applied to the concept of distance in the decision-making science (see e.g. Li, Sun, \& Zeng, 2018). The result of these combinations are the induced OWA operators with distances e.g. the induced ordered weighted averaging distance (IOWAD) operators introduced by (Merigó \& Casanovas, 2011), the induced aggregation operators developed by (Su, Zeng, \& Ye, 2013), the linguistic induced aggregation distance operators by (Zeng \& Weihua, 2012), and the fuzzy linguistic induced ordered weighted averaging Minkowski distance (FLIOWAMD) operator (Xian et al., 2016).

Motivated by the complex ordering mechanism of the induced OWA operators, the ideal set of arguments compared to individual options in the form of distances, the logarithmic aggregation operators presented firstly by (Zhou \& Chen, 2010), and the challenges presented in decision making processes while dealing with regions, this paper introduces a family of operators named multi region induced generalized ordered weighted averaging distance (MR-IOWLAD) operators. Since the appearance of the generalized ordered weighted logarithmic average operator, several extensions have appeared in the field of decision making such as the generalized logarithmic proportional averaging operators (Zhou, Chen, \& Liu, 2012), the generalized ordered weighted logarithmic harmonic averaging operators (Zhou, Tao, Chen, \& Liu, 2014), the induced generalized ordered weighted logarithmic averaging operator (Alfaro-García, Gil-Lafuente, \& Merigó, 2016) and the generalized ordered weighted logarithmic averaging distance (Alfaro-García, Merigó, Gil-Lafuente, \& Kacprzyk, 2018). The MR-IOWLAD operators developed in this work are designed to aid decision-making when a series of information linked to regions needs to be considered. Please observe that, when combined with multicriteria decision-making, the MR-IOWLAD utilizes its designed reordering mechanisms to find the most suitable candidate from a series of feasible alternatives (Zeng \& Xiao, 2018); these characteristic features allow for a practical assessment of widely complex and real-world oriented problems.

This study presents an in-depth exploration of the Hamming distance included in the MR-IOWLAD operator and its parameterized families, including the maximum and the minimum, in three different variants. The characterization of its weighting vector $W$ also considers the olympic MR-IOWLAD, the centered IOWLAD and the maximum entropy OWA. Another series of families is also explored by shifting the $V$ weighting vector; this mechanism allows for more complex formulations of the operator, such as the $\mathrm{MR}_{\mathrm{OWA}}{ }^{-}$ IOWLAD operator. Moreover, when designing operators for complex decision-making approaches, the MR-IOWLAD operator is combined with the mean average, the mean average distance, the weighted average, the OWA distance operator, the induced OWA operator, the induced OWA distance operator, the induced generalized OWA operator, and the induced generalized OWA distance operator to model wider problems when assessing regional problems. Furthermore, this paper introduces the IOWLAD and the generalized ordered weighted logarithmic averaging distance (IGOWLAD) operators, as well as their specific 
properties and families, including the parameterized cases when the lambda value changes. Finally, we show how the IGOWLAD operators relate to discrete Choquet integrals and the conditions for this combination.

The main advantage of this approach, including the induced vector and the Hamming distance, is that it provides a more general framework that contains the previous approaches as particular cases. Therefore, it presents a wider perspective that can be adapted to many different scenarios considering diverse information, and it can be reduced to some specific classical cases if the problem requires. The induced vector has been proven to be useful when assessing highly complex problems with the heterogeneous attitudinal character of the decision-makers. Additionally, the included distance measure mechanism aims to provide a useful tool when the problem is associated with the comparison of diverse alternatives and an ideal scenario.

The remainder of the paper is as follows. Section 1 presents the foundations of this study. Section 2 introduces the IOWLAD and MR-IOWLAD operators and their properties, families and characteristic weighting vectors. Section 3 presents the IGOWLAD operator and the measures used to characterize its $W$ weighting vector and its families depending on the lambda value. Section 4 briefly introduces the concept of IGOWLAD operators and Choquet integrals. Section 5 studies the general approach to solving decision-making problems with MR-IOWLAD, and a series of complex aggregation procedures are denominated multiregion logarithmic AGOP. Section 6 presents a numerical example of the application of the MRIOWLAD, and finally, this study presents its concluding comments.

\section{Preliminaries}

\subsection{The OWA operator}

The first aggregation operator to appear in the literature was the ordered weighted average OWA operator. When first introduced, the OWA was shown to be an advanced operator that included a series of specific families depending on the criteria, e.g., the minimum, the maximum and the average.

Definition 1. It is, in fact, a mapping $O W A: R^{n} \rightarrow R$, of $n$ dimensions that includes in its design a $w$ vector that must satisfy $w_{j} \in[0,1]$, and $\sum_{j=1}^{n} w_{j}=1$. The OWA operator follows
the formula:

$$
O W A\left(a_{1}, a_{2}, \ldots, a_{n}\right)=\sum_{j=1}^{n} w_{j} b_{j}
$$

where $b_{j}$ corresponds to the $j$ th largest element of $a_{i}$.

Since its introduction, the OWA has been widely adopted in several fields of knowledge. This has mainly occurred because of the inherent properties of the operator, i.e., boundedness, monotonicity, commutativity and idempotency. These properties, aligned to the nonlinearity given by the reordering of the arguments, have made this operator very popular among the scientific community. Please note that the OWA operator can be distinguished as ascending or descending depending on the reordering process that the operator follows. 


\subsection{The IOWA operator}

After the appearance of the OWA operator, many other extensions were also introduced. One of the foremost extensions that introduced the capacity of including complexity in the reordering mechanism of the operator was the induced ordered weighted average IOWA operator (see Zeng et al., 2018). This operator works on induced order variables that directly affect the ordering mechanism of a traditional OWA operator and is defined as follows:

Definition 2. The IOWA operator of dimension $n$, as the former operator, is the result of a map IOWA : $R^{n} \rightarrow R$, with a $W$ weighting vector such that the total sum yields 1 and must also be between 0 and 1 . This operator has a set of order-induced variables $u_{i}$, such that:

$$
\operatorname{IOWA}\left(\left\langle u_{1}, a_{1},\right\rangle \ldots,\left\langle u_{n}, a_{n}\right\rangle\right)=\sum_{j=1}^{n} w_{j} b_{j},
$$

where $\left(b_{1}, \ldots, b_{n}\right)$ is $\left(a_{1}, a_{2} \ldots, a_{n}\right)$ but reordered in a decreasing order following $u_{i}$.

\subsection{Hamming distance}

When assessing distance measures, one can find diverse tools in the literature (Li et al., 2018), e.g., the Euclidean distance, the Levenshtein distance, the Lee distance, and the DamerauLevenshtein distance. In the present paper, we use the Hamming distance; the main characteristic of this well-known similarity measure is its ability to measure the difference between two strings, elements or sets. To define this measure, assume two sets, e.g., $A=\left(a_{1}, a_{2}, \ldots, a_{n}\right)$ and $B=\left(b_{1}, b_{2}, \ldots, b_{n}\right)$; in this case, the weighted Hamming distance is:

Definition 3. A normalized Hamming distance of $n$ dimensions fits a mapping $W H D:[0,1]^{n} \times[0,1]^{n} \rightarrow[0,1]$ that includes an associated weighting vector $W$ of $n$ dimensions; this vector must satisfy $w_{j} \in[0,1]$, and the sum of the weights must equal 1 , following:

$$
W H D(A, B)=\left(\sum_{i=1}^{n} w_{i}\left|a_{i}-b_{i}\right|\right),
$$

where $a_{i}$ and $b_{i}$ are the $i$ th elements of the sets described in $A$ and $B$, respectively.

\subsection{GOWLAD operator}

Zhou and Chen (2010) introduced the generalized ordered weighted logarithmic averaging (GOWLA) operator. Motivated by that operator, Alfaro et al. (2018) introduced the generalized ordered weighted logarithmic averaging distance (GOWLAD) operator. GOWLAD is an extension of GOWLA proposed in 2010 and models the idea of comparing an ordered logarithmic set of elements to an ideal. The GOWLAD operator can be defined as:

Definition 4. A GOWLAD operator with $n$ dimensions is part of a mapping GOWLAD: $\Omega^{n} \times \Omega^{n} \rightarrow \Omega$ including a weighting vector $W$ of the same dimension $n$ with the constraint of having the sum of the weights equal 1 , and the total of $w_{j}$ must be between 0 and 1 , satisfying: 


$$
\operatorname{GOWLAD}\left(\left\langle x_{1}, y_{1}\right\rangle,\left\langle x_{2}, y_{2}\right\rangle, \ldots,\left\langle x_{n}, y_{n}\right\rangle\right)=\exp \left\{\left(\sum_{j=1}^{n} w_{j}\left(\ln b_{j}\right)^{\lambda}\right)^{\frac{1}{\lambda}}\right\}
$$

In this case, $b_{j}$ is the result of $\left|x_{i}-y_{i}\right|$ values of the GOWLAD $\left\langle x_{i}, y_{i}\right\rangle$, in decreasing order, following $\left|x_{i}-y_{i}\right|$. Please note that $\left|x_{i}-y_{i}\right|$ are all the variables but represented as individual distances. Additionally, here, $\lambda$ must satisfy $\lambda \in(-\infty, \infty)-\{0\}$.

\section{Multiregion aggregation operators with the IOWLAD}

The multiregion-induced ordered weighted logarithmic averaging distance (MR-IOWLAD) operator is an extension of the IOWLAD operator. The IOWLAD operator is introduced in this section. The MR-IOWLAD operator is designed to aid in decision-making processes when two or more regions, influenced by the characteristic distinctions of the countries in which they reside, need to be included in a specific problem. In this section, we will study the main characteristics, definitions, properties and families of the MR-IOWLAD operator using the characteristic weighting $W$ vector and the weighting $V$ vector.

\subsection{IOWLAD operator}

Definition 5. An induced OWLAD operator of $n$ dimension is a mapping IOWLAD: $\Omega^{n} \times \Omega^{n} \rightarrow \Omega$, which serves as an averaging operator with a characteristic weighting vector $W$, with the total sum of the weights equal to 1 and each $w_{j} \in[0,1]$, following:

$$
\operatorname{IOWLAD}\left(\left\langle u_{1}, x_{1}, y_{1}\right\rangle,\left\langle u_{2}, x_{2}, y_{2}\right\rangle, \ldots,\left\langle u_{n}, x_{n}, y_{n}\right\rangle\right)=\exp \left\{\sum_{j=1}^{n} w_{j}\left(\ln h_{j}\right)\right\},
$$

where $h_{j}$ represents the $j$ th largest variable of the $\left|x_{i}-y_{i}\right|$ reordered in decreasing order following the effect of the induced variables.

Example 1. Assume the following collection of arguments: $X=(25,51,48,61), Y=(43,10$, $37,32)$, an induced weighting vector $U=(33,19,52,21)$ and $W=(0.2,0.1,0.4,0.3)$. The result is as follows:

$$
\begin{aligned}
& \operatorname{IOWLAD}(\langle 33,25,43\rangle,\langle 19,51,10\rangle,\langle 52,48,37\rangle,\langle 21,61,32\rangle)= \\
& \exp \{0.2 \times(\ln |48-37|)+0.1 \times(\ln |25-43|)+0.4 \times(\ln |61-32|)+0.3 \times(\ln |51-10|)\}=25.27
\end{aligned}
$$

Please note that in this example, the arguments $\left|x_{i}-y_{i}\right|$ are ordered following the decreasing effect of the induced variables $u_{i}$.

It can be observed that this aggregation process is defined by the descending effect that the induced variables have on the result, which can also be differentiated as the descending induced ordered weighted logarithmic averaging distance DIOWLAD operator. As a counterpart, we can also differentiate the ascending induced ordered weighted logarithmic averaging distance AIOWLAD operator, where the effect of the induced variables is ordered from the smallest value to the greatest. 


\subsection{Multiregion IOWLAD operator}

Definition 6. A multiregion IOWLAD operator is a characteristic aggregation operator including a weighting vector $V$ of $p$ dimensions that must satisfy $\sum_{k=1}^{p} v_{k}=1$ and $v_{k} \in[0,1]$ and a weighting vector $W$ of $n$ dimensions such that $\sum_{j=1}^{n} w_{j}=1$, and $w_{j} \in[0,1]$, according to:

$$
M R-I O W L A D\left(\left(u_{1}, x_{1}^{1}, y_{1}^{1}\right), \ldots,\left(u_{n}, x_{n}^{p}, y_{n}^{p}\right)\right)=\exp \left\{\sum_{k=1}^{p} \sum_{j=1}^{n} v_{k} w_{j}\left(\ln b_{j}\right)\right\},
$$

where $b_{j}$ is the $\left|x_{i}-y_{i}\right|$ value of the MR-IOWLAD $\left(x_{i}, y_{i}\right)$, reordered by the influence of the induced variables $u_{n}$. The arguments $\left|x_{i}^{k}-y_{i}^{k}\right|$ are variables given by the information of each region in the form of individual distances.

Observe that here, the multiregion aggregation $v_{k}$ uses a weighted average to set the ponderation of the regions assessed; however, it is also possible to consider an OWA aggregation in the $v_{k}$ weighting vector. Furthermore, we can also use other OWA-related extensions, such as induced and heavy aggregation operators, to model other complex problems.

Please observe the behavior of the MR-IOWLAD operator in Figure 1. The graph illustrates 3 different states of the operator; first (blue) when $p=1, n=1$; second (red) in the case of $p=2, n=3$; and finally (green) under the circumstance of $p=10, n=10$. Note that for all cases, $v_{k}=1 / k$ and $w_{j}=1 / j$.

Example 2. Assuming the next set of arguments: $X^{1}=(18,3,28), Y^{1}=(21,18,6), X^{2}=(30$, $22,5), Y^{2}=(27,19,30), U=(5,10,6), W=(0.3,0.1,0.6), V=(0.7 .03)$. The result of the aggregation is as follows:

$$
\begin{aligned}
& M R-I O W L A D(\langle 5,18,21\rangle,\langle 10,3,18\rangle,\langle 6,28,6\rangle,\langle 5,30,27\rangle,\langle 10,22,19\rangle,\langle 6,5,30\rangle)= \\
& \exp \{0.7[0.3(\ln |3-18|)+0.1(\ln |28-6|)+0.6(\ln |18-21|)]+ \\
& 0.3[0.3(\ln |22-19|)+0.1(\ln |5-30|)+0.6(\ln |30-27|)]\}=5.15
\end{aligned}
$$

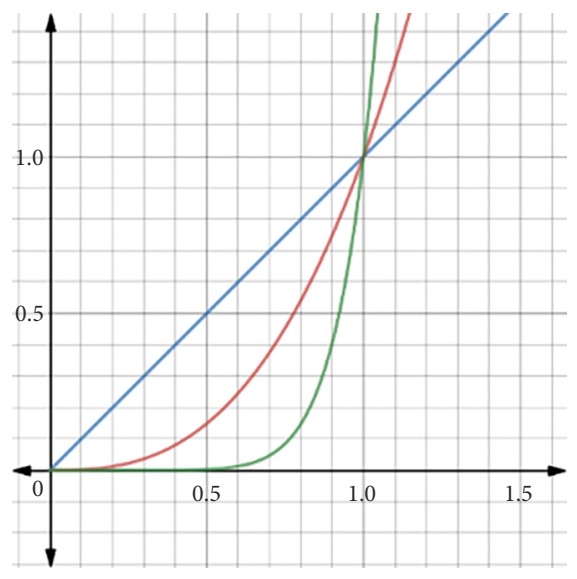

Figure 1. MR-IOWLAD operator behavior 
The MR-IOWLAD operator allows a complex aggregation designed to merge the opinions of the decision-makers in the form of induced variables $u_{i}$ and a characteristic weighting vector $W$ along with the representation of the importance vector $V$ that diverse regions and countries might have in a specific problem.

The MR-IOWLAD operator shares several properties of the OWLAD operator; however, the induced variable $u_{i}$ must be considered when describing its properties. In general, this operator is commutative, idempotent, bounded, monotonic, nonnegative and reflexive. The properties mentioned above can be proven by solving the following theorems:

Theorem 1. Commutative. By the distance measure, the $f$ function is the MR-IOWLAD operator; then, we have:

$$
f\left(\left\langle u_{1}, x_{1}, y_{1}\right\rangle, \ldots,\left\langle u_{n}, x_{n}, y_{n}\right\rangle\right)=f\left(\left\langle u_{1}, x_{1}, y_{1}\right\rangle, \ldots,\left\langle u_{n}, x_{n}, y_{n}\right\rangle\right) .
$$

Theorem 2. Monotonic, as the function preserves or reverses the given order. Let $\mathrm{f}$ be the characteristic function of an MR-IOWLAD operator; then, if $\left|x_{i}-y_{i}\right| \geq\left|c_{i}-d_{i}\right|$ for all $i$,

$$
f\left(\left\langle u_{1}, x_{1}, y_{1}\right\rangle, \ldots,\left\langle u_{n}, x_{n}, y_{n}\right\rangle\right) \geq f\left(\left\langle u_{1}, c_{1}, d_{1}\right\rangle, \ldots,\left\langle u_{n}, c_{n}, d_{n}\right\rangle\right) .
$$

Theorem 3. Bounded between the maximum and minimum values of the elements to be aggregated. If we assume the function $\mathrm{f}$ represents the MR-IOWLAD operator, then

$$
\min \left\{\left|x_{i}-y_{i}\right|\right\} \leq f\left(\left\langle u_{1}, x_{1}, y_{1}\right\rangle, \ldots,\left\langle u_{n}, x_{n}, y_{n}\right\rangle\right) \leq \max \left\{\left|x_{i}-y_{i}\right|\right\} .
$$

Theorem 4. Idempotent, as the operator can be applied several times without changing the result outside the original application. When the function $\mathrm{f}$ is the MR-IOWLAD operator and if $\left|x_{i}-y_{i}\right|=a_{i}$, for all $i$, then

$$
f\left(\left\langle u_{1}, x_{1}, y_{1}\right\rangle, \ldots,\left\langle u_{n}, x_{n}, y_{n}\right\rangle\right)=a .
$$

Theorem 5. Nonnegative, as the operator has positive values as the result. Let $\mathrm{f}$ be the MRIOWLAD operator; then, in this case,

$$
f\left(\left\langle u_{1}, x_{1}, y_{1}\right\rangle, \ldots,\left\langle u_{n}, x_{n}, y_{n}\right\rangle\right) \geq 0 .
$$

Theorem 6. Reflexivity, as every element is related to itself. Let $\mathrm{f}$ be the MR-IOWLAD operator; then,

$$
f\left(\left\langle u_{1}, x_{1}, y_{1}\right\rangle, \ldots,\left\langle u_{n}, x_{n}, y_{n}\right\rangle\right)=0 .
$$

Please observe that the MR-IOWLAD operator does not accomplish commutativity by the OWA operator because of the weighted average (WA) step that takes place in the aggregation. Additionally, note that the MR-IOWLAD operator does not always accomplish triangular inequality; in some specific cases, the operator behaves as described in the next formula,

$$
M R-I O W L A D(a, b)+M R-I O W L A D(b, c) \leq M R-I O W L A D(a, c) .
$$

In the next example, we present a case in which the MR-IOWLAD operator does not display triangular inequality.

Example 3. Let $a=(10,10,101,1,1), b=(5,5,51,1,1), c=(2,2,21,1,1)$ assuming a weighting vector $w=(0,0,1)$, a vector $v=(0.5,0.5)$ and an induced vector $u=(5,3,1)$. Then, the aggrega- 
tion for $M R-\operatorname{IOWLAD}(a, b)=6, M R-\operatorname{IOWLAD}(b, c)=2$ and $M R-\operatorname{IOWLAD}(a, c)=9$, thus showing that $6+2<9$, proving the MR-IOWLA operator does not satisfy the triangular inequality.

\subsection{Families of the MR-IOWLAD operators}

This section focuses on describing some of the operators that form the MR-IOWLAD families. In general terms and because of the characteristic design of the operator, we can study these families from two main standpoints. First, in this study, we analyze the weighting vector $W$, which includes the maximum, the minimum, the step, the olympic and the maximal entropy OWA (MEOWA) method. Second, we study the weighted $V$ vector, which includes the arithmetic case, and we propose some weighted vectors based on economic indicators. Finally, we offer some OWA extensions to characterize the vector.

\subsubsection{The weighting vector $\mathrm{V}$ in the MR-IOWLAD operator}

The design of the MR-IOWLAD operator includes a $V$ weighting vector that assists in the modeling of complex scenarios. In our case, this vector works as a differentiator of the heaviness in which some specific zones that share common elements, i.e., regions, exert over the phenomena that are being analyzed. Next, we propose some characterization of the $V$ weighting vector.

Remark 1. An arithmetic MR-IOWLAD is obtained when $v_{k}=1 / p$ for all $k$ satisfying $\sum_{k=1}^{p} v_{k}=1$ and $v_{k} \in[0,1]$.

Remark 2. Some MR-IOWLAD operators based on economic indicators include the GDP (gross domestic product) MR-IOWLAD, see, e.g., (Merigó, Peris-Ortíz, Navarro-García, \& Rueda-Armengot, 2016). This operator is obtained when $v_{1}$ is the $k t h$ largest GDP of the regions analyzed, following the rest in decreasing order; please note that $v_{k} \in[0,1]$ and the sum of all $v_{k}$ equals 1 . In the same order of ideas, the GDP-GR (GDP growth rate) MR-IOWLAD that follows $v 1$ is the $k$ th largest GDP growth rate over a fixed period, usually under constant prices based on a given year and the same restrictions as the GDP MR-IOWLAD. An example of a social indicator is the LT (literacy rate) MR-IOWLAD. In this case, we give the largest ponderation to the least illiterate region. In this case, the $v_{k}$ is the $k$ th region with the lowest illiteracy rate. Following the increasing order, the weighting vector needs to follow $\sum_{k=1}^{p} v_{k}=1$ and $v_{k} \in[0,1]$.

Remark 3. An interesting concept is choosing an OWA operator and all its parameterized families to characterize the $v_{k}$ weighting vector. An example of an operator in this complex scenario is the OWA MR-IOWLAD operator.

$$
M R_{O W A}-\operatorname{IOWLAD}\left(a_{n}, u_{n}, x_{n}, y_{n}\right)=\exp \left\{\sum_{j=1}^{n} \sum_{s=1}^{d} x_{j}\left(w_{s}\left(\ln D_{s}\right)\right)_{j}\right\},
$$

where $\left(w_{s}\left(\ln D_{s}\right)\right)_{j}$ corresponds to the $j$ th largest element of the $w_{s}\left(\ln D_{s}\right)$ and $D_{s}$ is the 
$\left|x_{i}-y_{i}\right|$ value of the MR-IOWLAD $\left(x_{i}, y_{i}\right)$, reordered by the influence of the induced variables $u_{n}$. The arguments $\left|x_{i}^{d}-y_{i}^{d}\right|$ are variables given by the information of each region in the form of individual distances. The elements $w_{s}\left(\ln D_{s}\right)$ have an associated weighting vector $w_{s}$ of $d$ dimensions such that the sum of the weights equals 1 and $w_{s} \in[0,1]$. Additionally, every argument $\left(w_{s}\left(\ln D_{s}\right)\right)_{j}$ includes an associated weighting vector $x_{j}$ that must satisfy $\sum_{j=1}^{n} x_{i}=1$ and $x_{i} \in[0,1]$, which is the largest weight $x_{i}$ ordered according to the $j$ th largest value of the $\left(w_{s}\left(\ln D_{s}\right)\right)_{j}$.

Please note that in the case of nonnormalization in the $v_{k}$ weighting vector, which is characterized by $V=\sum_{j=1}^{n} v_{k} \neq 1$ of its elements, then the MR-IOWLAD operator and its families can be normalized by applying:

$$
M R-I O W L A D\left(\left\langle u_{1}, x_{1}, y_{1}\right\rangle, \ldots,\left\langle u_{n}, x_{n}, y_{n}\right\rangle\right)=\exp \left\{\frac{1}{V} \sum_{k=1}^{p} \sum_{j=1}^{n} v_{k} w_{j} \ln \left(b_{j}\right)\right\} \text {, }
$$

where $V=\sum_{k=1}^{p} v_{k}$, thus achieving the normalization of the weighting vector.

\subsubsection{MR-IOWLAD families by the weighting vector $\mathrm{W}$}

The characteristic weighting vector $W$ plays a key role in the aggregation process of the MRIOWLAD operators. Some operators that can be formulated by shifting the characteristics of the $W$ weighting vector are described in the next remarks.

Remark 4. The maximum distance can be obtained in any of the next three scenarios:

- The maximum distance for the $W$ weighting vector: $w_{q}=1, w_{j}=0$ for all $j \neq q$ and $u_{q}=\max \left|x_{n}-y_{n}\right|$.

- The maximum distance for the weighting vector $V$, i.e., $v_{q}=\max \left(v_{k}\right)$.

- If both vectors match on the maximum, then the maximum distance is $w_{q}=1, w_{j}=$ 0 for all $j \neq q, u_{q}=\max \left|x_{i}^{a}-y_{i}^{a}\right|$ for all $i \neq 1, v_{q}=1$, for $v_{q}=\max \left|x_{n}^{k}-y_{n}^{k}\right|$, and $v_{k}=$ 0 , for all the others; here $\left|x_{n}^{k}-y_{n}^{k}\right|$ represents the maximum value of the variables in the shape of the individual distances for every region.

Remark 5. In complement, the minimum distance can also be differentiated in these three settings:

- The maximum distance considering only the $W$ weighting vector: $w_{q}=1, w_{j}=0$ for all $j \neq q$ and $u_{q}=\min \left|x_{n}-y_{n}\right|$.

- The maximum considering the $V$ weighting vector: $v_{q}=\min \left(v_{k}\right)$.

- When both vectors coincide on the min, then: $w_{q}=1, w_{j}=0$ for all $j \neq q$, $u_{q}=\min \left|x_{i}^{a}-y_{i}^{a}\right|$ for all $i \neq 1$, and the minimum value of all the regions assessed i.e., $v_{q}=1$, for $v_{q}=\min \left|x_{n}^{k}-y_{n}^{k}\right|, v_{k}=0$, for all the others; here, $\left|x_{n}^{k}-y_{n}^{k}\right|$ represents the maximum value of the variables in the shape of individual distances for every region. 
Remark 6. Other interesting families are achieved when:

- Let $w_{q}=1$ and $w_{j}=0$ for all $j \neq q$, and we only consider the $W$ weighting vector. The result is the MR-IOWLAD step. If we consider only the $V$ vector, then the MR-IOWLAD step is achieved when $v_{q}=1$, and $v_{k}=0$ for all $k \neq q$. If both coincide, then the step MR-IOWLAD is found when $w_{q}=1$, and $w_{j}=0$ for all $j \neq q$ and $v_{q}=1$, and $v_{k}=0$ for all $k \neq q$.

- The normalized logarithmic Hamming distance (NLHD) when only one region is in play appears when $w_{j}=\frac{1}{n}$, for all $q$. The NLHD when several regions are in play shows when: $w_{j}=\frac{1}{n}$, for all $q$ and $v_{p}=\frac{1}{k}$, for all $m$.

- The weighted logarithmic Hamming distance (WLHD) in a one-region problem is generated when the ordered position of $u_{i}$ is the same as the ordered position of $\left|x_{n}-y_{n}\right|$. When several regions are modeled, then the WLHD is obtained when the ordered position of $u_{i}$ is the same as the ordered position of $\left|x_{n}-y_{n}\right|$, and $v_{p}=\frac{1}{k}$, for all $m$.

- The OWLAD operator is reduced when $v_{a}=1, v_{k}=0$ for all $k \neq a$ and the ordered position of $u_{i}$ is the same as the ordered position of the values $\left|x_{n}-y_{n}\right|$, for all $i$, and there is only one region.

Remark 7. An olympic MR-IOWLAD is achieved under the following conditions:

- When we only consider the $W$ weighting vector region, then $w_{1}=w_{n}=0$ and $w_{j}=\frac{1}{(n-2)}$, for all $j-\{1, n\}$. If we only consider the $V$ weighting vector, then $v_{1}=$ 0 and $v_{k}=0$, and $v_{q}=\frac{1}{(k-2)}$, for all $k-\{1, k\}$. When both weighting vectors are in play, the olympic MR-IOWLAD is achieved by $w_{1}=w_{n}=0$, and $w_{j}=\frac{1}{(n-2)}$, for all $j-\{1, n\}, v_{1}=0$ and $v_{k}=0$, and $v_{q}=\frac{1}{(k-2)}$, for all $k-\{1, k\}$.

- Please observe that in the case of one region all the next apply: when $n=3$ or $n=$ 4 , the olympic IOWLAD is the median IOWLAD. In general terms, an olympic IOWLAD is described when $w_{j}=0$ for $j=1,2, \ldots, k, n, n-1, \ldots, n-k+1$, and for the others $w_{j}=\frac{1}{(n-2 k)}$, where $k<\frac{n}{2}$. When this occurs, if $k=1$, it is the usual olympic IOWLAD, whereas if $k=\frac{(n-1)}{2}$, we obtain the median IOWLAD. Also note that the opposite case of an olympic IOWLAD operator occurs when $w_{j}=\frac{1}{2 k}$ for $j=1,2, \ldots, k, n, n-1, \ldots, n-k+1$, and $w_{j}=0$, for all others, where $k<\frac{n}{2}$.

Remark 8. Some other families are the centered MR-IOWLAD operators. It can be said that an aggregation is centered if it follows the conditions of symmetry, strong decay and inclusiveness. Following the two scenarios:

- When the operator includes only one region, then symmetry is obtained when $w_{j}=w_{n+1-j}$. Strong decay is represented when $w_{j}<w_{j}$. Finally, inclusiveness is characterized by $w_{j}>0$. 
- When the operator includes more than one region, then symmetry is obtained when $w_{j}=w_{n+1-j}$ and $v_{k}=v_{k+1-j}$. Strong decay is represented when $i<j \leq \frac{(n+1)}{2}$, then $w_{i}<w_{j}$, and $v_{i}<v_{j}$. Finally, the inclusiveness is obtained when $w_{j}>0$ and $v_{j}>0$.

Remark 9. Other interesting methods for the characterization of the weighting vector $W$ can be represented when studying the maximal entropy. Please note that the maximal entropy OWA (MEOWA) can be obtained when $\beta=1$ in the next optimization problem:

$$
\text { maximize } H(\hat{V})=-\left(\beta \sum_{J=1}^{n} w_{j} \ln \left(w_{j}\right)+(1-\beta) \sum_{J=1}^{n} v_{i} \ln \left(v_{i}\right)\right) \text {, }
$$

s.t.

$$
\begin{aligned}
& \beta \sum_{J=1}^{n} w_{j}\left(\frac{n-j}{n-1}\right)+(1-\beta) \sum_{j=1}^{n} v_{j}\left(\frac{n-j}{n-1}\right)=\alpha(\hat{V}), 0 \leq \alpha(\hat{V}) \leq 1, \\
& \sum_{J=1}^{n} \hat{v}=1,0 \leq \hat{v} \leq 1, j=1,2, \ldots, n .
\end{aligned}
$$

Please note that many other families can be built depending on the weighting vector $W$. For other interesting operators that can be obtained following the methodology presented here, see, e.g., (Beliakov et al., 2007; Merigó \& Casanovas, 2011; Yager, 1993, 2003).

\section{IGOWLAD operator}

Definition 7. An IGOWLAD operator of dimension $n$ is a mapping IGOWLAD: $\Omega^{n} \times \Omega^{n} \rightarrow \Omega$ defined by an associated weighted vector $W$ of dimension $n$ such that the sum of the weights is equal to 1 and $w_{j} \in[0,1]$, according to the formula:

$$
\operatorname{IGOWLAD}\left(\left\langle u_{1}, x_{1}, y_{1}\right\rangle,\left\langle u_{2}, x_{2}, y_{2}\right\rangle, \ldots,\left\langle u_{n}, x_{n}, y_{n}\right\rangle\right)=\exp \left\{\left(\sum_{j=1}^{n} w_{j}\left(\ln b_{j}\right)^{\lambda}\right)^{\frac{1}{\lambda}}\right\},
$$

where $b_{j}$ is the $\left|x_{i}-y_{i}\right|$ value of the IGOWLAD $u_{i}, x_{i}, y_{i}$, reordered according to the induced variables $u_{i}$. The argument $\left|x_{i}-y_{i}\right|$ are variables represented in the form of individual distances, and $\lambda$ is a parameter satisfying $\lambda \in(-\infty, \infty)-\{0\}$.

Example 4. Assume the collection of arguments presented for Example 1 and a $\lambda=2$. Then,

$$
\begin{aligned}
& \text { IOWLAD }(\langle 33,25,43\rangle,\langle 19,51,10\rangle,\langle 52,48,37\rangle,\langle 21,61,32\rangle)= \\
& \exp \{[0.2 \times(\ln |48-37|) \wedge 2+0.1 \times(\ln |25-43|) \wedge 2+0.4 \times(\ln |61-32|) \wedge 2+ \\
& 0.3 \times(\ln |51-10|) \wedge 2] \wedge(1 / 2)\}=26.17 .
\end{aligned}
$$

The IGOWLAD operator can also consider regions and the weights they might have for a complex decision-making process. In this case, the formulation of the MR-IGOWLAD can be described as follows: 
Definition 8. An MR-IGOWLAD operator of $n$ dimension gives a mapping IGOWLAD: $\Omega^{n} \times \Omega^{n} \rightarrow \Omega$ with two weighting vectors; the first is a weighted vector $W$ of $n$ dimensions. This vector must satisfy that the sum of the weights is equal to 1 and all its elements are in the range 0 and 1 . Second, a $V$ weighting vector of $p$ dimension must satisfy $\sum_{k=1}^{p} v_{k}=1$
and $v_{k} \in[0,1]$, following:

$$
M R-I G O W L A D\left(u_{n}, x_{n}, y_{n}\right)=\exp \left\{\left(\sum_{k=1}^{p} \sum_{j=1}^{n} v_{k} w_{j}\left(\ln b_{j}\right)^{\lambda}\right)^{\frac{1}{\lambda}}\right\},
$$

where $b_{j}$ is the $\left|x_{i}-y_{i}\right|$ value of the MR-IOWLAD $\left(x_{i}, y_{i}\right)$, reordered by the influence of the induced variables $u_{n}$. The arguments $\left|x_{i}^{k}-y_{i}^{k}\right|$ are variables given by the information of each region in the form of individual distances.

Example 5. Assume the collection of arguments presented, for example, 2 and $\lambda=3$. Then,

$$
\begin{aligned}
& M R-I O W L A D(\langle 5,18,21\rangle,\langle 10,3,18\rangle,\langle 6,28,6\rangle,\langle 5,30,27\rangle,\langle 10,22,19\rangle,\langle 6,5,30\rangle)= \\
& \exp \{[0.7[0.3(\ln |3-18|) \wedge 3+0.1(\ln |28-6|) \wedge 3+0.6(\ln |18-21|) \wedge 3]+ \\
& \left.\left.0.3\left[0.3(\ln |22-19|) \wedge 3+0.1(\ln |5-30|)^{\wedge} 3+0.6(\ln |30-27|) \wedge 3\right]\right]^{\wedge}(1 / 3)\right\}=7.48 .
\end{aligned}
$$

\subsection{Characterization of the $W$ weighting vector}

An interesting topic to cover when presenting aggregation operators is the characterization of the weighting vector and the measures available for that purpose. Some classic measures

\begin{tabular}{|c|c|c|c|c|}
\hline Name & Acronym & Formula & & Description of the result \\
\hline Balance & $\operatorname{Bal}(W)$ & $\operatorname{Bal}(W)=\sum_{j=1}^{n} w_{j}\left(\frac{n+1-2 j}{n-1}\right)$ & (19) & $\begin{array}{l}\operatorname{Bal}(W)=-1: \text { minimum balance } \\
\operatorname{Bal}(W)=-1: \text { maximum balance }\end{array}$ \\
\hline $\begin{array}{l}\text { Degree } \\
\text { of orness }\end{array}$ & $\alpha(W)$ & $\alpha(W)=\left(\sum_{j=1}^{n} w_{j}\left(\frac{n-j}{n-1}\right)^{\lambda}\right)^{\frac{1}{\lambda}}$ & $(20)$ & $\begin{array}{l}\alpha(W)=1 \text { : optimistic criteria } \\
\alpha(W)=0: \text { pessimistic criterion } \\
\alpha(W)=0.5 \text { : the averaging criteria } \\
\text { is achieved }\end{array}$ \\
\hline $\begin{array}{l}\text { Diver- } \\
\text { gence }\end{array}$ & $\operatorname{Div}(W)$ & $\operatorname{Div}(W)=\sum_{j=1}^{n} w_{j}\left(-\alpha(W)+\frac{n-j}{n-1}\right)^{2}$ & $(21)$ & $\begin{array}{l}\text { This measure can be used as a com- } \\
\text { plement to the attitudinal character } \\
\text { and the entropy to correctly charac- } \\
\text { terize the weighting vector }\end{array}$ \\
\hline $\begin{array}{l}\text { Entropy } \\
\text { of dis- } \\
\text { persion }\end{array}$ & $H(W)$ & $H(W)=-\sum_{j=1}^{n} w_{j} \ln \left(w_{j}\right)$ & $(22)$ & $\begin{array}{l}\text { If } w_{j}=1 \text {, for any } j \text {, then: } H(W)=0 \text { : } \\
\text { minimum information being used } \\
\text { If } w_{j}=\left(\frac{1}{n}\right) \text { for all } j \text {, then the } \\
\text { maximum information is being } \\
\text { used }\end{array}$ \\
\hline
\end{tabular}
include the balance, the degree of orness, the divergence, and the entropy of dispersion. Please see Table 1 for detailed information.

Table 1. Characterization of the $W$ IGOWLAD weighting vector 
Example 6. Table 2. Includes the results of the diverse measures for the case of the IGOWLAD and the weighting vector $W=(0.2,0.1,0.4,0.3)$ presented in Example 1.

Table 2. Results for Example 6

\begin{tabular}{|l|c|c|c|c|}
\hline Measure & $B(W)$ & $\alpha(W)$ & $\operatorname{Div}(W)$ & $H(W)$ \\
\hline Result & -0.2 & 0.4 & 0.13 & 1.28 \\
\hline
\end{tabular}

Please note that the measures presented here do not cover all the characteristics that logarithmic functions exhibit. Please see the general characterizations and the transformations to the R-scale presented in Alfaro et al. (2018).

\subsection{Analysis of the $\lambda$ vector}

The $\lambda$ vector, in the specific case of the IGOWLAD operator, generates a series of families that range from the logarithmic geometric averaging operator to the maximum and the minimum. Table 3 presents a summary of some interesting particular cases when varying the $\lambda$ vector.

Table 3. IGOWLAD operator families by the $\lambda$ vector. Note that for all the cases, $b_{j}$ is the $\left|x_{i}-y_{i}\right|$ value of the GOWLAD $x_{i}, y_{i}$, reordered by the induced effect of the variable $u_{i}$

\begin{tabular}{|l|l|c|c|c|}
\hline \multicolumn{1}{|c|}{ Families } & Acronym & \multicolumn{1}{|c|}{ Formula } \\
\hline$\lambda \rightarrow 0$ & $\begin{array}{l}\text { Induced ordered } \\
\text { weighted logarithmic } \\
\text { geometric averaging } \\
\text { distance operator }\end{array}$ & IOWLGAD & $\operatorname{IGOWLAD}\left(x_{n}, y_{n}\right)=\exp \left\{\prod_{j=1}^{n}\left(\ln \left(b_{j}\right)\right)^{w_{j}}\right\} \quad$ (23) \\
\hline$\lambda=-1$ & $\begin{array}{l}\text { Induced ordered } \\
\text { weighted logarithmic } \\
\text { harmonic averaging } \\
\text { distance operator }\end{array}$ & IOWLHAD & IGOWLAD $\left(x_{n}, y_{n}\right)=\exp \left\{\sum_{j=1}^{n}\left(\frac{w_{j}}{\ln b_{j}}\right)\right\}$
\end{tabular}


Example 7. Following the arguments described in Example 1, we present results for all the IGOWLAD operators displayed in Table 4:

Table 4. Families of the IGOWLA operator

\begin{tabular}{|c|c|c|c|c|c|c|c|}
\hline$\lambda$ & $\rightarrow 0$ & -1 & 1 & 2 & 3 & $\infty$ & $-\infty$ \\
\hline Result & 24.31 & 23.31 & 25.27 & 26.17 & 27.01 & $\rightarrow 41$ & $\rightarrow 11$ \\
\hline
\end{tabular}

\section{IGOWLAD operators with Choquet integrals}

When assessing distance measures and induced aggregation operators, it is interesting to explore the work of (Bolton, Gader, \& Wilson, 2008; Choquet, 1954; Mesiar, Kolesárová, Bustince, Dimuro, \& Bedregal, 2016; Mesiar, 1995; Tan \& Chen, 2010). Based on these studies, it is possible to create a new operator using discrete Choquet integrals, specifically the induced Choquet logarithmic distance aggregation (ICLD) operator and the induced generalized Choquet logarithmic distance aggregation (IGCLD) operator. To introduce these new operators, let us first define the concept of the fuzzy distance measure.

Definition 9. Assume $X$ to be a universal set of arguments $X=\left\{x_{1}, x_{2}, \ldots, x_{n}\right\}$ and $P$ to be the power set of $X$, i.e., the combination of all the elements. Then, a fuzzy measure on $X$ is a set function $m: P(X) \rightarrow[0,1]$, satisfying:

$$
m(\varnothing)=0, m(X)=1 \text { (boundary conditions) and, }
$$

If $A, B \in P(X)$ and $A \subseteq B$ then $m(A) \leq m(B)$ (monotonicity).

As shown in (Choquet, 1954), the Choquet integral can be defined as:

Definition 10. Let $f$ be a positive real-value function $f: X \rightarrow R^{+}$and $m$ be a fuzzy measure on $X$. The (discrete) Choquet integral of $f$ with respect to $m$ is:

$$
C_{m}\left(f_{1}, \ldots, f_{n}\right)=\sum_{i=l}^{n} f_{(i)}\left[m\left(A_{(i)}\right)-m\left(A_{(i-1))}\right]\right.
$$

here, $(\cdot)$ represents a permutation on $X$ in the way that $f_{(1)} \geq f_{(2)} \geq \ldots \geq f_{(n)}$; thus, $f_{(i)}$ is the $i$ th largest value in the set $\left\{f_{1}, f_{2}, \ldots, f_{n}\right\}$. Hence, $A_{(i)}=\left\{x_{1}, x_{2}, \ldots, x_{n}\right\}$ when $i \geq l$ and $A_{(0)}=\varnothing$.

Based on the definitions established above, we introduce the ICLD and the IGCLD operators. Please note that both utilize distance measures; hence, they compare two sets of the defined variables. Additionally, the characteristic-induced property allows us to perform a complex decision-making process. First, the ICLD operator can be defined as:

Definition 11. Assume $m$ to be a fuzzy measure on the finite space $X$. The induced Choquet logarithmic distance averaging operator of $n$ dimensions is a function ICLD: $R^{n} \times R^{n} \times R^{n} \rightarrow \times R$, such that:

$$
\operatorname{ICLD}\left(u_{n}, x_{n}, y_{n}\right)=\exp \sum_{j=1}^{n}\left[m\left(A_{i}\right)-m\left(A_{i-1}\right)\right]\left(\ln D_{j}\right)
$$

where $D_{j}$ is the $\left|x_{i}-y_{i}\right|$ value of the ICLD $\left(u_{i}, x_{i}, y_{i}\right)$, ordered by the influence of the $u_{n}$ orderinducing variables. The arguments $\left|x_{i}-y_{i}\right|$ are variables gathering information about each 
region to be addressed in the form of individual distances, satisfying $A_{(i)}=\left\{x_{1}, x_{2}, \ldots, x_{n}\right\} \geq 1$; and $A_{(0)}=\varnothing$.

Following, we introduce a more general perspective of the operator. The IGCLD operator, which introduces a more complex view of the aggregation, can be defined as:

Definition 12. Let $m$ be a fuzzy measure on $X$. An induced generalized Choquet logarithmic distance averaging operator of dimension $n$ is a characteristic function IGCLD: $R^{n} \times R^{n} \times R^{n} \rightarrow R$, satisfying:

$$
\operatorname{IGCLD}\left(x_{n}, y_{n}\right)=\exp \left\{\left(\sum_{j=1}^{n}\left[m\left(A_{i}\right)-m\left(A_{i-1}\right)\right]\left(\ln D_{j}\right)\right)^{1 /}\right\},
$$

where $D_{j}$ is the $\left|x_{i}-y_{i}\right|$ value of the $\operatorname{ICLD}\left(u_{i}, x_{i}, y_{i}\right)$, in decreasing order, following the largest $u_{i} ; u_{i}$ are the order-inducing variables that affect the behavior of the aggregation. The elements $\left|x_{i}-y_{i}\right|$ are variables with information for each region to be aggregated as individual distances, such that $A_{(i)}=\left\{x_{1}, x_{2}, \ldots, x_{n}\right\} \geq 1$; and $A_{(0)}=\varnothing$.

Please note that this approach yields a whole new series of operators, e.g., the induced quasi-arithmetic Choquet logarithmic distance operators, the induced moving averages Choquet logarithmic distance operators, and numerous sets of families that can be generated following the previous methods explained in the former sections.

\section{Theoretical approach}

The MR-IOWLAD and the families presented in this study have a wide range of applications in several fields of knowledge, e.g., engineering, artificial intelligence, business economics and statistics (León-Castro, Avilés-Ochoa, \& Gil-Lafuente, 2016; Maldonado, Merigó, \& Miranda, 2018). One of the main fields of application is in decision-making (Blanco-Mesa, Merigó, \& Gil-Lafuente, 2017). The MR-IOWLAD is designed to aid in complex decision-making processes, mainly in situations where regions or countries must be evaluated. This is due to the inherent characteristics that make a region more attractive in terms of a desired goal; to see an example of financial decision making in diverse market regions, please see (Zeng, 2017).

In this section, we present the main approach used to assess a problem with MR-IOWLAD. We also include several other tools that can be helpful for decision making, including not only the weighted average as the main driver for region categorization but also some OWA operators to extend the complexity in the problems to be assessed.

\subsection{Multicriteria multiregion logarithmic AGOP}

When modeling decision-making problems with the MR-IOWLAD operator, a useful insight is to add other operators to the aggregation process. This option allows us to include multicriteria arguments to assess a wider range of situations. Table 5 presents a combination of the MR-IOWLAD operator with a series of other operators, including the mean average, the mean average distance, the weighted average, the OWA operator, the OWA distance operator, the induced OWA operator, the induced OWA distance operator, the induced generalized OWA operator, and the induced generalized OWA distance operator. 


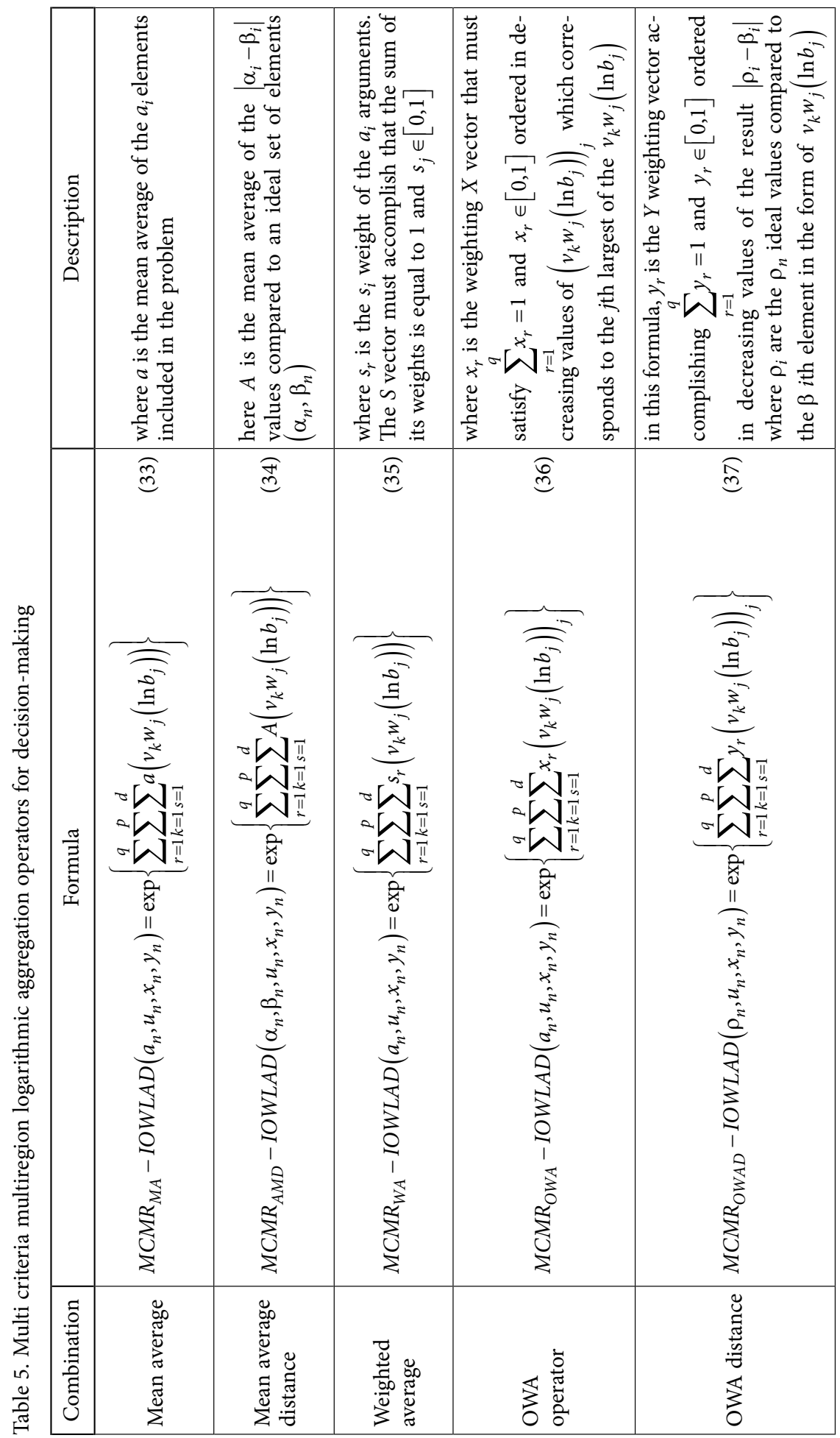




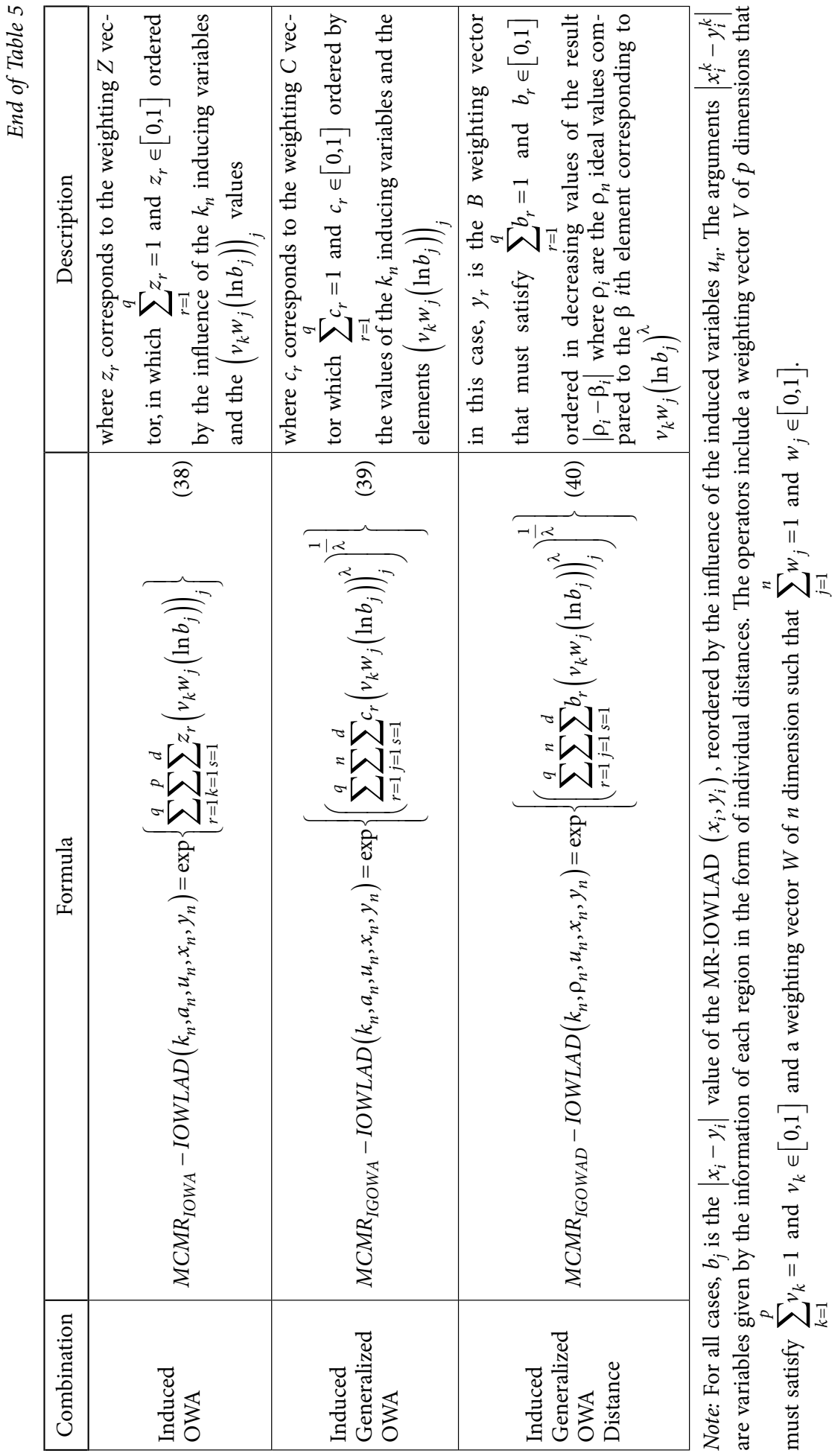


The results of the combinations are the multi-criteria multi-region IOWLAD operators. These sets of complex aggregation operators allow the complex ordering of the arguments to be aggregated. This option generates a wider understanding of the elements that surround the decision-making process. Please observe that these set of operators can be expanded to make other combinations following the methodology presented in this paper.

\subsection{Decision-making with multicriteria MR-IOWLAD}

There are several methods to target decision-making problems utilizing averaging operators, see, e.g., (Avilés-Ochoa, León-Castro, Perez-Arellano, \& Merigó, 2018). In the present study, we propose a stepwise process to assess a decision-making problem using the MCMRIOWLAD operator, which can be summarized as follows:

Step 1. Set a limited group of elements $A=\left\{A_{1}, A_{2}, \ldots, A_{n}\right\}$ as countries to represent a region, and another group of $C=\left\{C_{1}, C_{2}, \ldots, C_{n}\right\}$ to be set as characteristics. Both sets of elements create the matrix $\left(x_{h i}\right)_{m \times n}$. Assume that $R=\left\{R_{1}, R_{2}, \ldots, R_{n}\right\}$ is a finite set of regions to be addressed. There must be a payoff matrix $\left(x_{h i}^{(k)}\right)_{m \times n}$ for each region; this payoff matrix can be obtained by experts or secondary sources of information.

Step 2. Set a level of the characteristics that an ideal region must reach. In this paper, we propose $I$ as the ideal value that each characteristic represented in the subset $C_{i}$ must satisfy; please observe that the characteristics must be evaluated as $y_{i} \in[1, \infty] ; i=1,2, \ldots, n$, is a number between 1 and infinity for the $i$ th characteristic.

Step 3. Set the order induced variables $\left(u_{h i}\right)_{m \times n}$ to be used when describing each alternative $h$ and each characteristic $i$. Also establish both a weighting $W=\left\{w, w_{2}, \ldots, w_{n}\right\}$ vector and a $V=\left\{v_{1}, v_{2}, \ldots, v_{n}\right\}$ weighting vector; for each case, the vectors must satisfy that the sum of the weights is equal to 1 and $w_{j} \in[0,1]$, and $v_{k} \in[0,1]$.

Step 4. Apply a simple average or any of the proposed multicriteria multiregion IOWLAD operators to aggregate the retrieved information about the countries. The result is a collective payoff matrix of regions $R$. Note that more complex aggregations can be obtained if we select a different method to aggregate the information in this matrix, e.g., the WA or the OWA operator. Please observe that a normalization of the data is required if the characteristics are of a diverse nature.

Step 5. Using the collective results matrix and the ideal region vector, compare both to obtain the individual distances; the aim is to present a numeric set that represents the existing distance between the ideal region and the different options available.

Step 6. Solve for the multicriteria MR-IOWLAD operator as described in Table 5; please note that in this proposal, each region is preferred following the $V$ weighting vector, which is a weighted average on each $R$. Observe that any of the families described in the former sections can be applied depending on the problem to be assessed.

Step 7. Finally, rank all the evaluated options and compare the obtained information. Here, it is suggested to create a compiled table to aid in visualization for fast decision-making. 
Please note that the logarithmic nature of the operator requires the arguments given for the aggregation to be in the $y_{i} \in[1, \infty]$ range. If there is a need to evaluate elements within the range $y_{i} \in[0,1]$, please see Alfaro et al. (2018), where the reader can find a series of methods explaining how to assess such a problem; specifically, see the transformation to the R-scale.

\section{Numerical example}

To exemplify the advances of the use of an MCMR-IOWLAD operator, this section proposes an illustrative example considering information retrieved from the United Nations (UN) World Statistics (United Nations, 2017). In this example, we aim to locate the region that better adjusts to a set of ideal arguments given by the decision makers of a media entertainment company that is willing to expand their operations to a new region.

Step 1. For exemplifying purposes, we will follow the established UN geographic regions, which comprise a set of $54 A=\left\{A_{1}, A_{2}, \ldots, A_{n}\right\}$ countries in 18 different regions $R=\left\{R_{1}, R_{2}, \ldots, R_{n}\right\}$ of the continents: Africa, Americas, Asia, Europe and Oceania (OCN). Please see Table 6 for the detailed set of countries selected per region. Please observe that the company is willing to take information of 3 countries as representative of a whole region. Please note that the regions can include as many countries as needed. The objective of the company is to analyze the selected regions under a set of ideal arguments following the next $C=\left\{C_{1}, C_{2}, \ldots, C_{n}\right\}$ group of characteristic economic and social indicators: Total population (millions of inhabitants), (TP); Gross domestic product (million current US\$), (GDP); Mobile-cellular subscriptions (per 100 inhabitants), (MCS), Individuals using the Internet (per 100 inhabitants), (IUI); GDP growth rate (annual \%, const. 2005 prices), (GDPG); Population growth rate (average annual \%), (PGR). The information retrieved for each region and social and economic indicators can be found in Table 6.

Step 2. The media producing company is searching for a region that fits into the general strategy of the firm that includes a fair penetration of mobile communications and a well-established Internet infrastructure. Additionally, the company seeks a region with a high economic growth rate and a significantly growing population. For that purpose, the decision-makers are asked to establish an ideal set of arguments $y_{i}$, in this case: MCS $=68$, $\mathrm{IUI}=86, \mathrm{GDPG}=58, \mathrm{PGR}=56$.

Step 3. Due to specific requirements and the attitudinal character of the executives, it is necessary to prioritize the economic growth variable, then the penetration of mobile telecommunications; then, it is necessary to consider the population growth and finally the Internet infrastructure. To assess such requirements, an induced vector $u_{i}$ is set to follow $\mathrm{MCS}=8, \mathrm{IUI}=4, \mathrm{GDPG}=10, \mathrm{PGR}=6$, and a $W$ weighting vector $(0.5,0.25,0.15,0.10)$. All of this information needs to be aggregated following the preferences of the decisionmakers towards the selected regions. In this case, the directive requires the weight of the regions to follow the GDP per capita. To accomplish this requisite, a $v_{k}$ vector is introduced based on the following order: Africa: $\mathrm{NA}=0.20, \mathrm{EA}=0.10, \mathrm{MA}=0.10, \mathrm{SA}=0.50, \mathrm{WA}=$ 0.10 ; Americas: $\mathrm{NAM}=0.50, \mathrm{CAM}=0.20, \mathrm{SAM}=0.30$; Asia: $\mathrm{CAS}=0.10, \mathrm{EAS}=0.20$, $\mathrm{SAS}=0.10, \mathrm{SEAS}=0.10$, WAS $=0.50$; Europe: $\mathrm{EEUR}=0.10, \mathrm{NEUR}=0.50, \mathrm{SEUR}=0.10$, WEUR $=0.30$; Oceania: $\mathrm{OCN}=1.00$. 


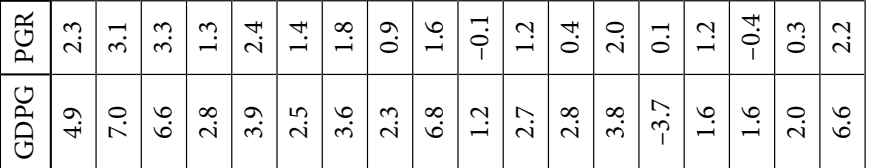

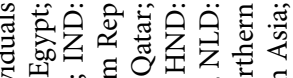

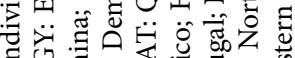

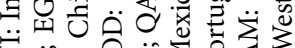

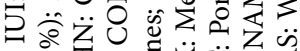

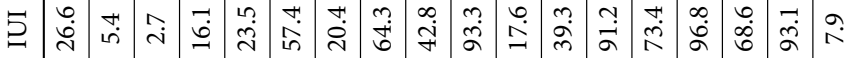
\% n ¿

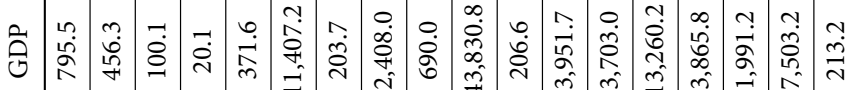

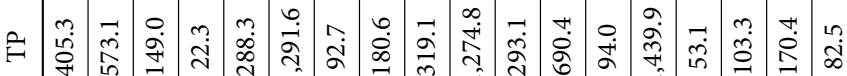

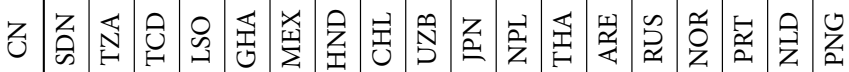

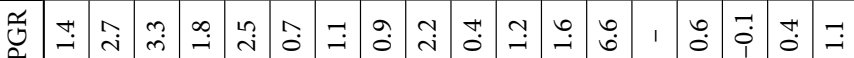

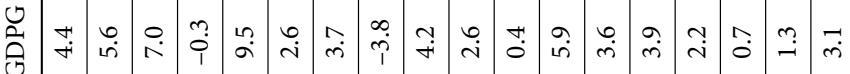

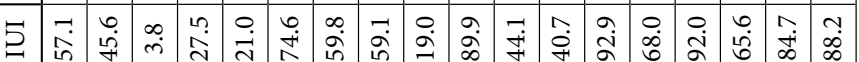

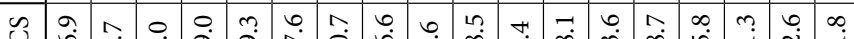

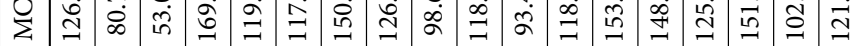

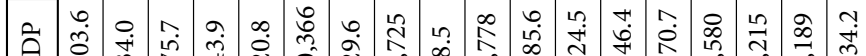

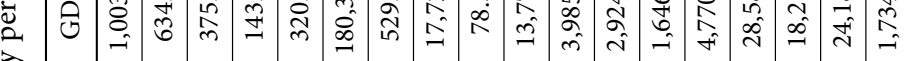

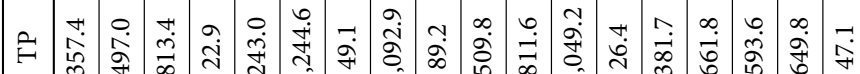
岕 Z

总

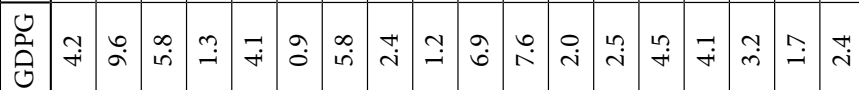

S

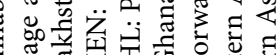

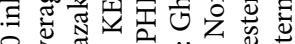

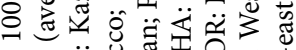

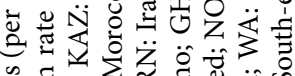

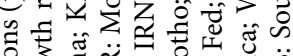

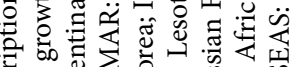
ड़

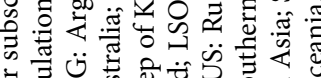

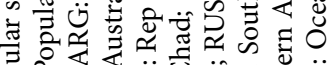
寻

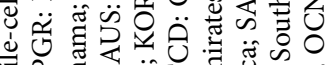

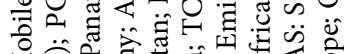

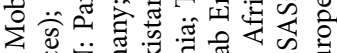

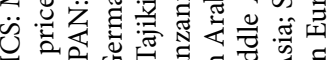

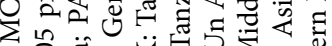

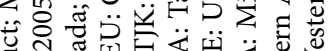

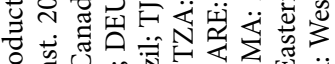

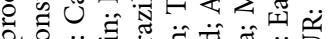

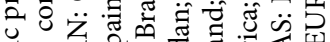
ज过 की

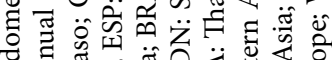

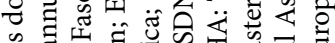

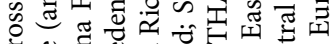

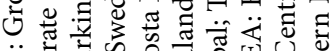

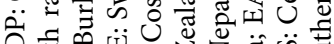

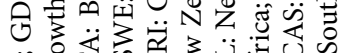

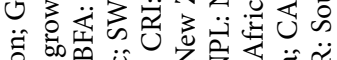

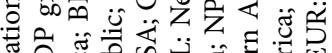

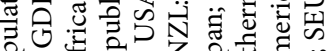

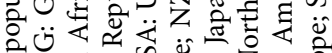

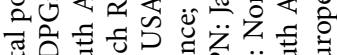

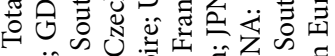

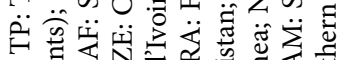
的焉

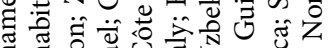

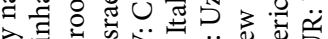

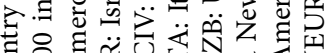

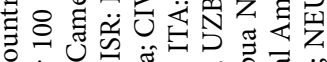

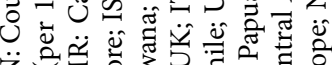

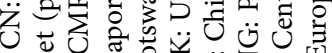
药

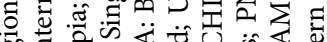

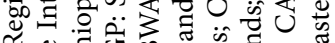

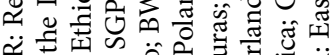
$\ddot{\sim} \mp$ 出

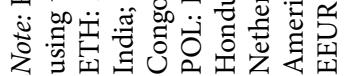


Step 4. With all the information retrieved, we decide to perform an $M C M R_{M A}$-IOWLAD operator. In this case, we first need to aggregate the information presented in Table 6 into a collective results matrix using a simple mean average. Table 7 gathers the collective results. As the characteristics are diverse in nature, we perform the normalization of the data. Table 8 collects the results for the normalized data.

Following steps 5 and 6 , we perform the $\mathrm{MCMR}_{\mathrm{MA}}$-IOWLAD operator. Please observe that in this case, we gather the collective data as a simple mean average, but we can use any of the multiregion logarithmic aggregation operators presented in section 5.1 for decisionmaking. Table 8 presents the results of the aggregation operator gathering all the requirements mentioned before for every region in each continent assessed.

Please note that the reordering process of the induced variables affects the result of the aggregation. When the MCMR $\mathrm{MA}$-IOWLAD operator is considered, it can be observed (Step 7) that the preferred region for the media company is Oceania $\succ$ Asia $\succ$ Africa $\succ$ Americas $\succ$ Europe.

Table 7. Collective results

\begin{tabular}{|c|c|c|c|c|c|c|c|c|}
\hline $\mathrm{C}$ & $\mathrm{R}$ & $\mathrm{TP}$ & GDP & GDP/TP & MCS & IUI & GDPG & PGR \\
\hline \multirow{5}{*}{ Africa } & $\mathrm{NA}$ & 173,826 & 495,822 & 2.9 & 102.8 & 39.9 & 4.5 & 2.0 \\
\hline & EA & 211,967 & 168,944 & 0.8 & 66.5 & 20.9 & 7.4 & 2.8 \\
\hline & MA & 120,294 & 75,994 & 0.6 & 55.0 & 9.1 & 6.5 & 3.1 \\
\hline & SA & 61,242 & 330,970 & 5.4 & 99.5 & 20.5 & 1.3 & 1.5 \\
\hline & WA & 72,322 & 80,297 & 1.1 & 109.9 & 18.6 & 5.8 & 2.6 \\
\hline \multirow{3}{*}{ Americas } & NAM & 490,247 & $20,730,180$ & 42.3 & 94.9 & 73.5 & 2.0 & 1.0 \\
\hline & CAM & 18,270 & 125,455 & 6.9 & 140.1 & 43.8 & 4.4 & 1.5 \\
\hline & SAM & 271,614 & $2,645,730$ & 9.7 & 133.3 & 64.3 & 0.3 & 0.9 \\
\hline \multirow{5}{*}{ Asia } & CAS & 59,036 & 258,611 & 4.4 & 119.7 & 44.9 & 4.1 & 1.8 \\
\hline & EAS & $1,587,983$ & $16,919,406$ & 10.7 & 112.2 & 77.8 & 3.6 & 0.3 \\
\hline & SAS & $1,449,648$ & $2,535,460$ & 1.7 & 89.7 & 29.2 & 3.6 & 1.2 \\
\hline & SEAS & 179,665 & 980,351 & 5.5 & 130.0 & 54.0 & 3.6 & 1.2 \\
\hline & WAS & 20,361 & 834,350 & 41.0 & 158.2 & 87.7 & 3.3 & 3.4 \\
\hline \multirow{4}{*}{ Europe } & EEUR & 192,779 & $1,988,238$ & 10.3 & 146.0 & 74.2 & 1.6 & 0.1 \\
\hline & NEUR & 81,398 & $3,740,275$ & 46.0 & 123.3 & 93.1 & 2.6 & 0.9 \\
\hline & SEUR & 116,044 & $3,213,657$ & 27.7 & 123.2 & 71.0 & 1.8 & -0.2 \\
\hline & WEUR & 164,130 & $6,532,864$ & 39.8 & 114.3 & 88.5 & 1.7 & 0.3 \\
\hline Oceania & $\mathrm{OCN}$ & 37,408 & $1,425,591$ & 38.1 & 100.4 & 60.2 & 4.0 & 1.6 \\
\hline
\end{tabular}

Note: C: Continent; R: Region; TP: Total population; GDP: Gross domestic product; MCS: GDP/TP: Gross domestic product per capita; Mobile-cellular subscriptions (per 100 inhabitants); IUI: Individuals using the Internet (per 100 inhabitants); GDPG: GDP growth rate (annual \%, const. 2005 prices); PGR: Population growth rate (average annual \%); NA: Northern Africa; EA: Eastern Africa; MA: Middle Africa; SA: Southern Africa; WA: Western Africa; NAM: Northern America; CAM: Central America; SAM: South America; CAS: Central Asia; EAS: Eastern Asia; SAS: Southern Asia; SEAS: Southeastern Asia; WAS: Western Asia; EEUR: Eastern Europe; NEUR: Northern Europe; SEUR: Southern Europe; WEUR: Western Europe; OCN: Oceania. 
Table 8. Normalized collective results

\begin{tabular}{|c|c|c|c|c|c|c|c|}
\hline $\mathrm{C}$ & $\mathrm{R}$ & MCS & IUI & GDPG & PGR & V & $\mathrm{MCMR}_{\mathrm{MA}}$-IOWLAD \\
\hline \multirow{5}{*}{ Africa } & NA & 64.99 & 42.81 & 60.81 & 57.84 & 0.20 & \multirow{5}{*}{15.47} \\
\hline & EA & 42.02 & 22.41 & 100.00 & 82.35 & 0.10 & \\
\hline & MA & 34.77 & 9.74 & 87.39 & 91.18 & 0.10 & \\
\hline & SA & 62.89 & 22.01 & 17.12 & 44.12 & 0.50 & \\
\hline & WA & 69.46 & 20.01 & 78.83 & 77.45 & 0.10 & \\
\hline \multirow{3}{*}{ Americas } & NAM & 60.02 & 78.92 & 27.03 & 30.39 & 0.50 & \multirow{3}{*}{16.43} \\
\hline & CAM & 88.60 & 47.03 & 59.01 & 45.10 & 0.20 & \\
\hline & SAM & 84.30 & 69.01 & 4.05 & 27.45 & 0.30 & \\
\hline \multirow{5}{*}{ Asia } & CAS & 75.68 & 48.21 & 54.95 & 52.94 & 0.10 & \multirow{5}{*}{13.00} \\
\hline & EAS & 70.96 & 83.57 & 48.20 & 7.84 & 0.20 & \\
\hline & SAS & 56.69 & 31.39 & 48.20 & 35.29 & 0.10 & \\
\hline & SEAS & 82.19 & 58.02 & 48.20 & 36.27 & 0.10 & \\
\hline & WAS & 100.00 & 94.13 & 44.59 & 100.00 & 0.50 & \\
\hline \multirow{4}{*}{ Europe } & EEUR & 92.29 & 79.71 & 21.17 & 1.96 & 0.10 & \multirow{4}{*}{19.92} \\
\hline & NEUR & 77.93 & 100.00 & 35.59 & 25.49 & 0.50 & \\
\hline & SEUR & 77.89 & 76.20 & 24.77 & -6.86 & 0.10 & \\
\hline & WEUR & 72.24 & 94.99 & 22.52 & 8.82 & 0.30 & \\
\hline Oceania & OCN & 63.48 & 64.67 & 54.50 & 47.06 & 1 & 5.14 \\
\hline
\end{tabular}

Note: C: Continent; R: Region; MCS: Mobile-cellular subscriptions (per 100 inhabitants); IUI: Individuals using the Internet (per 100 inhabitants); GDPG: GDP growth rate (annual \%, const. 2005 prices); PGR: Population growth rate (average annual \%); $V: V$ weighting vector depending on the GDP/TP; NA: Northern Africa; EA: Eastern Africa; MA: Middle Africa; SA: Southern Africa; WA: Western Africa; NAM: Northern America; CAM: Central America; SAM: South America; CAS: Central Asia; EAS: Eastern Asia; SAS: Southern Asia; SEAS: Southeastern Asia; WAS: Western Asia; EEUR: Eastern Europe; NEUR: Northern Europe; SEUR: Southern Europe; WEUR: Western Europe; OCN: Oceania.

Additionally, it can be observed that in this case, the preferred option is the one with the minimum result, i.e., the minimum distance between the ideal set or ideal arguments of the decision-makers and the data retrieved from the statistical sources analyzed. By using this method, we can achieve high complexity in the modeling of the problem, specifically the complexity of the differences in regions, as well as the preferences of the directive towards the strategy to follow and, most importantly, an ideal set of arguments that work as an objective for the whole model.

Tables 9 and 10 present the comparative results between the $M_{M A}$-IOWLAD operator and other distance operators, including the normalized Hamming distance (NHD), the weighted Hamming distance (WHD), the ordered weighted average distance (OWAD) and the induced ordered weighted average distance (IOWAD). The results conclude in a clear selection of Oceania and Asia as the preferred markets; only the OWAD presents a different market (Americas) as the second option, and the rest of the selected markets vary. Mathematically, the IOWAD and the $\mathrm{MR}_{\mathrm{MA}}$-IOWLAD are the most similar operators; however, there is a clear distinction between the last 3 options, i.e., Europe, the Americas and Africa. 
Table 9. Comparative table

\begin{tabular}{|l|c|c|c|c|c|}
\hline & NHD & WHD & OWAD & IOWAD & MRMA-IOWLAD \\
\hline Africa & 28.82 & 25.31 & 41.38 & 25.73 & 15.47 \\
\hline Americas & 21.21 & 22.49 & 28.66 & 24.36 & 16.43 \\
\hline Asia & 20.85 & 19.67 & 29.73 & 17.50 & 13.01 \\
\hline Europe & 22.73 & 23.49 & 30.52 & 24.14 & 19.92 \\
\hline Oceania & 9.57 & 7.50 & 13.93 & 6.35 & 5.14 \\
\hline
\end{tabular}

Table 10. Comparative aggregated results

\begin{tabular}{|l|l|}
\hline NHD & Oceania $\succ$ Asia $\succ$ Americas $\succ$ Europa $\succ$ Africa \\
\hline WHD & Oceania $\succ$ Asia $\succ$ Americas $\succ$ Europe $\succ$ Africa \\
\hline OWAD & Oceania $\succ$ Americas $\succ$ Asia $\succ$ Europe $\succ$ Africa \\
\hline IOWAD & Oceania $\succ$ Asia $\succ$ Europe $\succ$ Americas $\succ$ Africa \\
\hline MR $_{\text {MA }}$-IOWLAD & Oceania $\succ$ Asia $\succ$ Africa $\succ$ Americas $\succ$ Europe \\
\hline
\end{tabular}

This effect is produced because of the construction of the operators and the logarithmic properties of the $M R_{M A}$-IOWLAD operator. The mathematical construction of the $\mathrm{MR}_{\mathrm{MA}^{-}}$ IOWLAD operator includes both the $V$ and the $W$ weighting vectors and only the second IOWAD operator, and the logarithmic properties of the $\mathrm{MR}_{M A}$-IOWLAD operator generate a sufficient effect to change the order of the selected markets. It is observable in this case that both the variance and the standard deviation of the $\mathrm{MR}_{\mathrm{MA}}$-IOWLAD operator are lower than the results of the other operators.

\section{Conclusions}

This paper presents the IOWLAD and MR-IOWLAD operators, as well as their families, properties, and relevant particular cases. The MR-IOWLAD operator has its foundations in the generalized ordered weighted averaging logarithmic averaging operators, the distance OWA operators and the induced OWA operators. The main motivation for the MR-IOWLAD operator relies on the increasing influence that regions exert on the economic, social and political environment of the world and the exponentially cumulative sets of elements that require modeling to properly assess these highly changing problems. The advantages of this hybrid operator specifically intended for multiregion problems rely on its flexible design, which allows the fusion of different weighted elements under diverse criteria and an ideal set of arguments. When put into practice, the MR-IOWLAD treats multiregion aggregation problems considering the attitudinal character of the decision-makers. Moreover, the MRIOWLAD operator can weight regions according to the specific conditions of the problem, heterogeneous information and diverse data sources. Furthermore, the notion of distance in the form of the Hamming metric allows the operator to compare the alternatives given to a set of optimal elements. This feature allows the decision-maker to introduce a complex con- 
struction of the model and has been proven useful in diverse applications, such as selecting an ideal portfolio of financial products and human resource selection procedures. Because of its design, the MR-IOWLAD operator provides a general framework that includes previous approaches as particular cases, which offers a wider perspective that can be adopted to several scenarios and at the same time can be reduced to some specific classic cases when required by the particularities of the problem.

This paper analyses the main properties of the MR-IOWLAD operators. It has been proven to be commutative (by the distance measure), idempotent, bounded, monotonic, nonnegative and reflexive. Please note that the operator does not accomplish commutativity by the OWA operator. In this study, we also present diverse families of the MR-IOWLAD operator in two ways. The first is the characterization of the $W$ weighting vector, including the minimum, the maximum, the olympic and the centered MR-IOWLAD. Second, from the perspective of the $V$ weighting vector, the arithmetic MR-IOWLAD along with some basic economic indicator operators and the $\mathrm{MR}_{\mathrm{OWA}}$-IOWLAD operators are described.

Furthermore, this paper introduces some generalizations and extensions of the IOWLAD operators. The induced generalized ordered weighted averaging distance (IGOWLAD) operator is described and further characterized by its weighting vector, resulting in balance, degree of orness, divergence and entropy of dispersion. Moreover, we present some interesting families depending on the associated $\lambda$ vector, including operators such as IOWLGAD, IOWLHAD, IOWLAD, IOWLQAD, IOWLCAD, the maximum and the minimum. An interesting extension also presented in this paper is the inclusion of Choquet integrals in the configuration of the IGOWLAD; here, the induced Choquet logarithmic distance averaging operator and the generalized induced Choquet logarithmic distance averaging operator are described.

When combined with multicriteria decision making, the MR-IOWLAD utilizes its designed mechanisms to select the best candidate from a feasible pool of alternatives. This approach leads to the composition of several new multicriteria multiregion IOWLAD operators oriented to a diverse set of practical applications, including problems where a single alternative requires preference according to the heterogeneous attitudinal character of diverse decision-makers, regional information and ideal scenarios. For these kinds of applications, this paper presents a theoretical approach to multicriteria decision making with MR-IOWLAD operators, including the mean average, the mean average distance, the weighted average, the OWA operator, the OWA distance, the induced OWA, the induced generalized OWA and the induced generalized OWA distance, to characterize the arguments to be assessed in the aggregation process. These complex formulations aid decision-makers in exploring new forms of information inclusion and modeling complex situations with attitudinal orientations.

Finally, this paper presents an illustrative example to demonstrate the capabilities of MRIOWLAD. The example takes information from the UN World Database for regions around the globe, and through a series of requirements, the model includes information from diverse regions to select the best alternative from an ideal set or arguments. The results of the $\mathrm{MR}_{\mathrm{MA}}$-IOWLAD operator are compared with those of other well-known operators, such as the normalized Hamming distance (NHD), the weighted Hamming distance (WHD), the ordered weighted average distance (OWAD) and the induced ordered weighted average 
distance (IOWAD). In general, all the operators agree on the first 2 selections; however, the mathematical construction of the $\mathrm{MR}_{\mathrm{MA}}$-IOWLAD operator and its logarithmic properties show a clear difference with the last 3 selections, and in a general comparison, considering that the data and the information introduced to the model, the variance and standard deviation of the results are lower than those of the rest of the operators.

Future research is needed to include some other interesting options to categorize the regions in the aggregation process and to deepen the study on the logarithmic properties of the operator and the inclusion of complex tools designed to assess further data, such as uncertain and linguistic information.

\section{Acknowledgements}

This research is part of the project "Red Iberoamericana para la Competitividad, Innovación y Desarrollo" (REDCID) number 616RT0515 in "Programa Iberoamericano de Ciencia y Tecnología para el Desarrollo" (CYTED).

\section{Disclosure statement}

The authors declare there is no competing, financial, professional, or personal interests from any other parties in relation to the work presented.

\section{References}

Acemoglu, D. (2009). Introduction to modern economic growth. New Jersey: Princeton University Press. Alfaro-García, V. G., Gil-Lafuente, A. M., \& Merigó, J. M. (2016). Induced generalized ordered weighted logarithmic aggregation operators. In 2016 IEEE Symposium Series on Computational Intelligence (SSCI) (pp. 1-7). Athens, Greece. https://doi.org/10.1109/SSCI.2016.7850012

Alfaro-García, V. G., Merigó, J. M., Gil-Lafuente, A. M., \& Kacprzyk, J. (2018). Logarithmic aggregation operators and distance measures. International Journal of Intelligent Systems, 33(7), 1488-1506. https://doi.org/10.1002/int.21988

Avilés-Ochoa, E., León-Castro, E., Perez-Arellano, L. A., \& Merigó, J. M. (2018). Government transparency measurement through prioritized distance operators. Journal of Intelligent \& Fuzzy Systems, 34(4), 2783-2794. https://doi.org/10.3233/JIFS-17935

Batabyal, A. A., \& Yoo, S. J. (2018). Schumpeterian creative class competition, innovation policy, and regional economic growth. International Review of Economics and Finance, 55, 86-97. https://doi.org/10.1016/j.iref.2018.01.016

Beliakov, G., Bustince, H., \& Calvo, T. (2016). A practical guide to averaging functions (Vol. 329). Springer International Publishing. https://doi.org/10.1007/978-3-319-24753-3

Beliakov, G., Pradera, A., \& Calvo, T. (2007). Aggregation functions: a guide for practitioners (Vol. 221). Springer Berlin Heidelberg.

Blanco-Mesa, F., León-Castro, E., \& Merigó, J. M. (2018). Bonferroni induced heavy operators in ERM decision-making: A case on large companies in Colombia. Applied Soft Computing, 72, 371-391. https://doi.org/10.1016/j.asoc.2018.08.001

Blanco-Mesa, F., Merigó, J. M., \& Gil-Lafuente, A. M. (2017). Fuzzy decision making: A bibliometricbased review. Journal of Intelligent \& Fuzzy Systems, 32, 2033-2050.

https://doi.org/10.3233/JIFS-161640 
Bolton, J., Gader, P., \& Wilson, J. N. (2008). Discrete choquet integral as a distance metric. IEEE Transactions on Fuzzy Systems, 16(4), 1107-1110. https://doi.org/10.1109/TFUZZ.2008.924347

Chen, S. J., \& Chen, S. M. (2003). A new method for handling multicriteria fuzzy decision-making problems using FN-IOWA operators. Cybernetics and Systems, 34(2), 109-137. https://doi.org/10.1080/01969720302866

Chiclana, F., Herrera-Viedma, E., Herrera, F., \& Alonso, S. (2007). Some induced ordered weighted averaging operators and their use for solving group decision-making problems based on fuzzy preference relations. European Journal of Operational Research, 182(1), 383-399. https://doi.org/10.1016/j.ejor.2006.08.032

Choquet, G. (1954). Theory of capacities. Annales de l'institut Fourier, 5, 131-295. https://doi.org/10.5802/aif.53

Florida, R. (2002). The rise of the creative class. New York: Basic Books.

Florida, R. (2005). The flight of the creative class. New York: Harper Business. https://doi.org/10.4324/9780203997673

Florida, R., Gulden, T., \& Mellander, C. (2008). The rise of the mega-region. Cambridge Journal of Regions, Economy and Society, 1(3), 459-476. https://doi.org/10.1093/cjres/rsn018

Florida, R., Mellander, C., \& Stolarick, K. (2008). Inside the black box of regional development - human capital, the creative class and tolerance. Journal of Economic Geography, 8(5), 615-649. https://doi.org/10.1093/jeg/lbn023

Grossman, G. M., \& Helpman, E. (1993). Innovation and growth in the global economy. Cambridge: MIT Press.

Grossman, G. M., \& Helpman, E. (2015). Globalization and growth. American Economic Review, 105(5), 100-104. https://doi.org/10.1257/aer.p20151068

Hamming, R. W. (1950). Error-detecting and error-correcting codes. Bell System Technical Journal, 29, 147-160. https://doi.org/10.1002/j.1538-7305.1950.tb00463.x

He, X. R., Wu, Y. Y., Yu, D., \& Merigó, J. M. (2017). Exploring the ordered weighted averaging operator knowledge domain: A bibliometric analysis. International Journal of Intelligent Systems, 32, 11511166. https://doi.org/10.1002/int.21894

León-Castro, E., Avilés-Ochoa, E. A., \& Gil-Lafuente, A. M. (2016). Exchange rate USD/MXN forecast through econometric models, time series and HOWMA operators. Economic Computation \& Economic Cybernetics Studies \& Research, 50(4), 135-150.

León-Castro, E., Avilés-Ochoa, E., Merigó, J. M., \& Gil-Lafuente, A. M. (2018). Heavy moving averages and their application in econometric forecasting. Cybernetics and Systems, 49(1), 26-43. https://doi.org/10.1080/01969722.2017.1412883

Li, Z., Sun, D., \& Zeng, S. (2018). Intuitionistic fuzzy multiple attribute decision-making model based on weighted induced distance measure and its application to investment selection. Symmetry, 10(7), 261. https://doi.org/10.3390/sym10070261

Lv, K., Yu, A., Gong, S., Wu, M., \& Xu, X. (2017). Impacts of educational factors on economic growth in regions of China: a spatial econometric approach. Technological and Economic Development of Economy, 23(6), 827-847. https://doi.org/10.3846/20294913.2015.1071296

Maldonado, S., Merigó, J. M., \& Miranda, J. (2018). Redefining support vector machines with the ordered weighted average. Knowledge-Based Systems, 148, 41-46. https://doi.org/10.1016/j.knosys.2018.02.025

Merigó, J. M., \& Casanovas, M. (2011). Decision-making with distance measures and induced aggregation operators. Computers and Industrial Engineering, 60(1), 66-76.

https://doi.org/10.1016/j.cie.2010.09.017 
Merigó, J. M., \& Gil-Lafuente, A. M. (2010). New decision-making techniques and their application in the selection of financial products. Information Sciences, 180(11), 2085-2094.

https://doi.org/10.1016/j.ins.2010.01.028

Merigó, J. M., Peris-Ortíz, M., Navarro-García, A., \& Rueda-Armengot, C. (2016). Aggregation operators in economic growth analysis and entrepreneurial group decision-making. Applied Soft Computing Journal, 47, 141-150. https://doi.org/10.1016/j.asoc.2016.05.031

Merigó, J. M., \& Yager, R. R. (2013). Generalized moving averages, distance measures and OWA operators. International Journal of Uncertainty, Fuzziness and Knowledge-Based Systems, 21(04), 533-559. https://doi.org/10.1142/S0218488513500268

Mesiar, R. (1995). Choquet-like integrals. Journal of Mathematical Analysis and Applications, 194(2), 477-488. https://doi.org/10.1006/jmaa.1995.1312

Mesiar, R., Kolesárová, A., Bustince, H., Dimuro, G. P., \& Bedregal, B. C. (2016). Fusion functions based discrete choquet-like integrals. European Journal of Operational Research, 252(2), 601-609. https://doi.org/10.1016/j.ejor.2016.01.027

$\mathrm{Su}, \mathrm{W} ., \mathrm{Zeng}, \mathrm{S} .$, \& Ye, X. (2013). Uncertain group decision-making with induced aggregation operators and euclidean distance. Technological and Economic Development of Economy, 19(3), 431-447. https://doi.org/10.3846/20294913.2013.821686

Sucháček, J., Seda, P., Friedrich, V., \& Koutský, J. (2017). Regional aspects of the development of largest enterprises in the Czech Republic. Technological and Economic Development of Economy, 23(4), 649-666. https://doi.org/10.3846/20294913.2017.1318314

Tan, C., \& Chen, X. (2010). Induced choquet ordered averaging operator and its application to group decision making. International Journal of Intelligent Systems, 25(1), 59-82. https://doi.org/10.1002/int.20388

United Nations. (2017). World Statistics Pocketbook 2017 edition (41st ed.). New York: United Nations Publications. https://doi.org/10.18356/c983bdf2-en

Wei, G., \& Zhao, X. (2012). Some induced correlated aggregating operators with intuitionistic fuzzy information and their application to multiple attribute group decision making. Expert Systems with Applications, 39(2), 2026-2034. https://doi.org/10.1016/j.eswa.2011.08.031

Xian, S. D., Sun, W. J., Xu, S. H., \& Gao, Y. Y. (2016). Fuzzy linguistic induced OWA minkowski distance operator and its application in group decision making. Pattern Analysis and Applications, 19(2), 325-335. https://doi.org/10.1007/s10044-014-0397-3

Xu, Z. S., \& Chen, J. (2008). Ordered weighted distance measure. Journal of Systems Science and Systems Engineering, 17(4), 432-445. https://doi.org/10.1007/s11518-008-5084-8

Yager, R. R. (1988). On ordered weighted averaging aggregation operators in multicriteria decisionmaking. IEEE Transactions on Systems, Man and Cybernetics B, 18(1), 183-190. https://doi.org/10.1109/21.87068

Yager, R. R. (1993). Families of OWA operators. Fuzzy Sets and Systems, 59(2), 125-148. https://doi.org/10.1016/0165-0114(93)90194-M

Yager, R. R. (2003). Induced aggregation operators. Fuzzy Sets and Systems, 137(1), 59-69. https://doi.org/10.1016/S0165-0114(02)00432-3

Yager, R. R., \& Filev, D. P. (1999). Induced ordered weighted averaging operators. IEEE Transactions on Systems, Man, and Cybernetics, Part B: Cybernetics, 29(2), 141-150. https://doi.org/10.1109/3477.752789

Zeng, S. (2017). Pythagorean fuzzy multiattribute group decision making with probabilistic information and owa approach. International Journal of Intelligent Systems, 32(11), 1136-1150.

https://doi.org/10.1002/int.21886 
Zeng, S., Llopis-Albert, C., \& Zhang, Y. (2018). A novel induced aggregation method for intuitionistic fuzzy set and its application in multiple attribute group decision making. International Journal of Intelligent Systems, 33(11), 2175-2188. https://doi.org/10.1002/int.22009

Zeng, S., Su, W., \& Zhang, C. (2016). Intuitionistic fuzzy generalized probabilistic ordered weighted averaging operator and its application to group decision making. Technological and Economic Development of Economy, 22(2), 177-193. https://doi.org/10.3846/20294913.2014.984253

Zeng, S., \& Xiao, Y. (2018). A method based on topsis and distance measures for hesitant fuzzy multiple attibute decision making. Technological and Economic Development of Economy, 24(3), 969-983. https://doi.org/10.3846/20294913.2016.1216472

Zeng, S., \& Su, W. H. (2011). Intuitionistic fuzzy ordered weighted distance operator. Knowledge-Based Systems, 24(8), 1224-1232. https://doi.org/10.1016/j.knosys.2011.05.013

Zeng, S., \& Weihua, S. (2012). Linguistic induced generalized aggregation distance operators and their application to decision making. Economic Computation and Economic Cybernetics Studies and Research, 46(2), 155-172.

Zhou, L., \& Chen, H. (2010). Generalized ordered weighted logarithm aggregation operators and their applications to group decision making. International Journal of Intelligent Systems, 25(7), 683-707. https://doi.org/10.1002/int.20419

Zhou, L., Chen, H., \& Liu, J. (2012). Generalized logarithmic proportional averaging operators and their applications to group decision making. Knowledge-Based Systems, 36, 268-279. https://doi.org/10.1016/j.knosys.2012.07.006

Zhou, L., Tao, Z., Chen, H., \& Liu, J. (2014). Generalized ordered weighted logarithmic harmonic averaging operators and their applications to group decision making. Soft Computing, 19(3), 715-730. https://doi.org/10.1007/s00500-014-1295-8

Zwick, R., Carlstein, E., \& Budescu, D. V. (1987). Measures of similarity among fuzzy concepts: a comparative analysis. International Journal of Approximate Reasoning, 1(2), 221-242.

https://doi.org/10.1016/0888-613X(87)90015-6 